\title{
Efficacy of Different Oocytes Harvesting Methods on Retrieval and Quality of Oocyte from Ovaries of Local Cows
}

\author{
Hashm M. AL.Rubaei ${ }^{\mathrm{a}}$ \\ Hyder M. Abd Ali ${ }^{b}$ \\ ${ }^{a, b}$ Al-Musaib Technical College , Al-Furat Al-Awst Technical University, 51009 \\ Babylon, Iraq \\ Drhashem48@yahoo.com
}

Submission date:- 3/6/2018 Acceptance date:- 23/7/2018 Publication date:- 11/12/2018

Keywords: cows, oocyte, slicing, puncture, aspiration of follicle.

\begin{abstract}
The aim of this study was to investigate the effect of different oocytes harvesting methods on retrieval and quality of oocyte from ovarian of local cows. The ovaries $(n=600)$ were collected from 300 non-pregnant cows their ages ranged between (3-10 years old), slaughtered at abattoir of Babylon province during the period between September 2017 to March 2018 . The oocytes were collected by slicing method, punture method and aspiration of follicle method and classified according to layers of cumulus cells and the homogenous of cytoplasm into three groups, first group : good quality oocytes with more than 3 layers of cumulus cells and homogenous of cytoplasm, second group : fair quality oocytes with less than 3 layers of cumulus cells and homogeneous of cytoplasm, third group : poor quality oocytes, denuded oocyte from cumulus cells with heterogeneous cytoplasm. The results showed that the total number of oocytes recovered and the number of oocytes recovered per ovary were significantly higher $(\mathrm{P}<0.05)$ by using slicing method (1639 and $8.195 \pm 1.03$ respectively) compared with the Puncture (923 and $4.610 \pm 0.86$ respectively ) and aspiration of follicle method (776 and $3.880 \pm 0.34$ respectively). The results of study also indicated that the total number of oocytes recovered, the average number of oocyte per ovary and the percentage of good recovered by slicing method $(751,3.750 \pm 0.95$ and $45.90 \%$ respectively) and puncture technique $(399,1.99 \pm 0.03$ and $43.30 \%$ respectively) were significantly higher $(\mathrm{P}<0.05)$ compared with aspiration of follicle $(299,1.14 \pm 0.01$ and $29.60 \%$ respectively). We conclude from this study that slicing method is the appropriate and good method for oocyte recovering with ideal morphological aspect and quality.
\end{abstract}

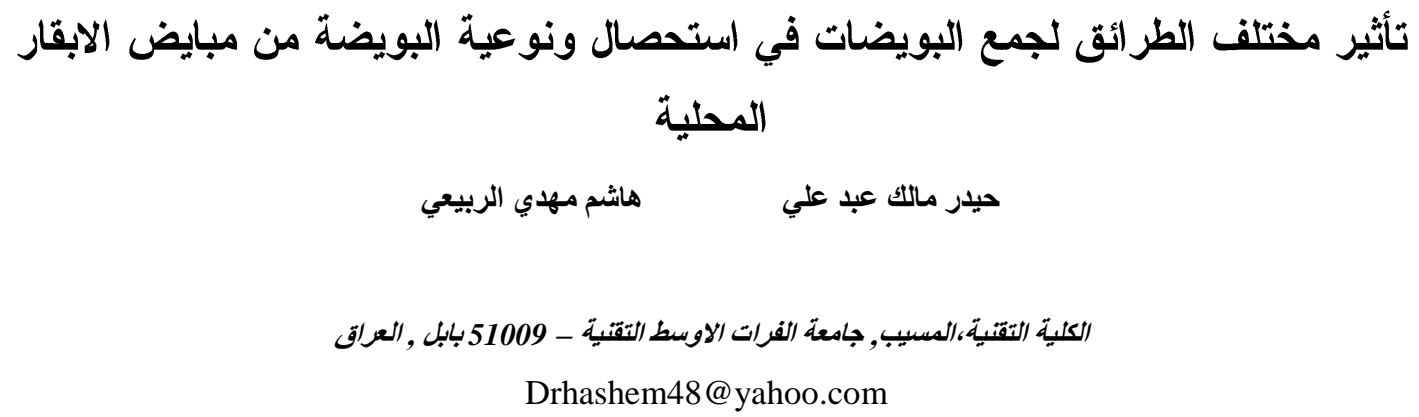

هدفت الدراسة الحالية لبحث تأثير ثلاث طر ائق لجمع البويضات في إستحصال ونوعية البويضة من مبايض الابقار المحلية .جمع 600 مبيض فيض فئ من 300 بقرة بعمر 3 - 10 سنوات غير حامل ذُبحت في مجازر محافظة بابل للمدة من أيلول 2017 لغاية أذار طريقة تشريح المبيض (Plicing) وطريقة تقب المبيض (Puncture) وطريقة سحب الجريبة (Aspiriation of follicle) , وقُسمت طبقاً لعدد طبقات 
الخلايا الركمية المبيضية (Cumulus cells) وتجانس الهيولي (Cytoplasm) على ثلاثة مجاميع, الاولى: بويضات جيدة محاطة بأكثر من ثلاث

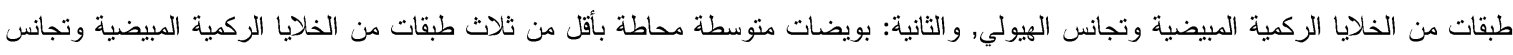

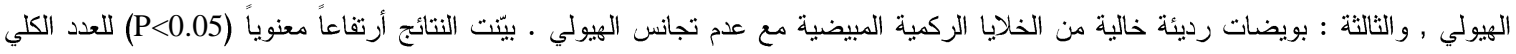

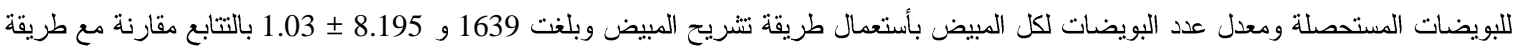

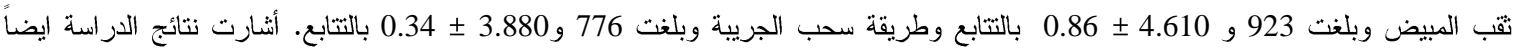
أرتفاعاً معنوياً (P<0.05) للعدد الكلي للبويضات ومعدل عدد البويضات لكل مبيض ونسبة البويضات الجيدة المستحصلة بطريقة تشريح المبيض وبلغت

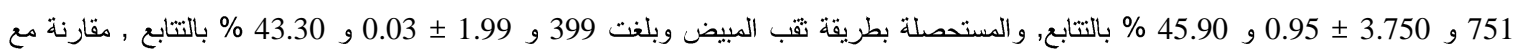
طريقة سحب الجريبة وبلغت 299 و 1.14 × 0.01 و 29.60 \% بالتتابع. يستتتج من هذه الدراسة أن طريقة تتُريح المبيض هي الطريقة المناسبة والجيدة لأستحصال البويضات وبأعداد كثيرة وذات شكل ونو عية جيدة. الكلمات الدالة: الابقار , البويضة, تشريح المبيض, ثقب المبيض, سحب الجزيبة.

تغادر بأستمرار نسبة قليلة من الجريبات الأولية الموجودة في المبيض عند الولادة , مرحلة السكون ( Resting stage) وتبدأ بالنمو , وان

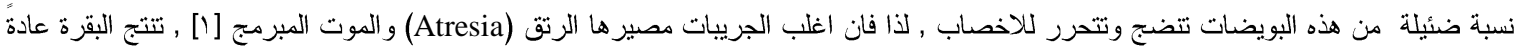

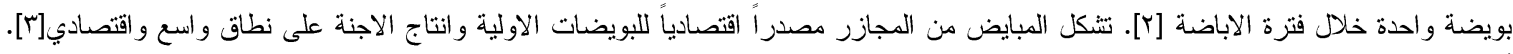
تُعد مبايض المجازر المصدر الارخص والاوفر للحصول على البويضات الاولية للثثيات والتي تستعمل في الابحاث الفسلجية والتقنيات الاحيائية

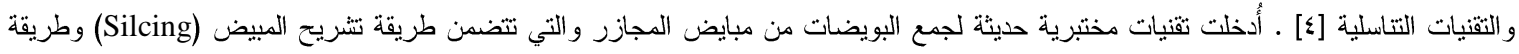
تقب المبيض (Puncture) وطريقة سحب الجريبة (Aspiration of follicle) اذ يمكن بوساطتها الحصول على البويضات بنوعية جيدة واعداد كثيرة

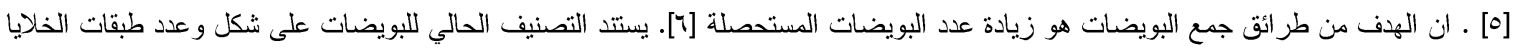

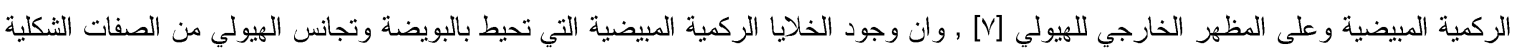

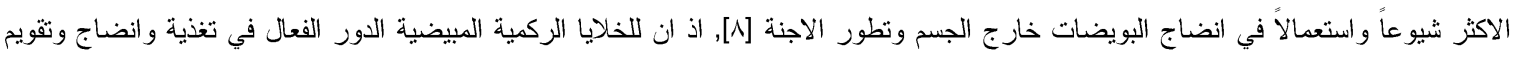

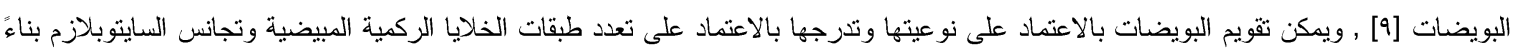

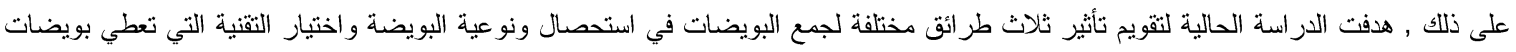
ذات شكل ونو عية جيدة وبأقل التكاليف.

\section{r

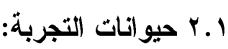

أنجزت الدراسة في مختبرات قسم تقنيات الانتاج الحيواني في الكلية التقنية / المسيب للمدة من ايلول 2017 لغاية آذار 2018 أزيل الجهاز

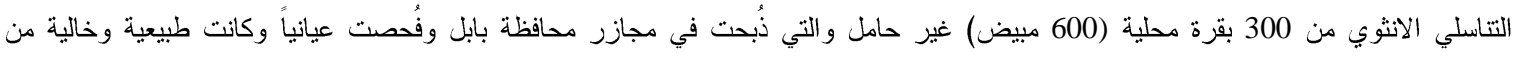

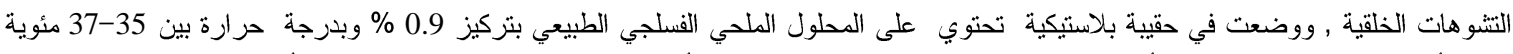
[§]. ونُقلت الى المختبر بساعتين. أُزيلت المبايض بوساطة مقص وملقط معقم ونُظفت من الانسجة العالقة والأربطة وغُسلت بمحلول الملح الفسلجي

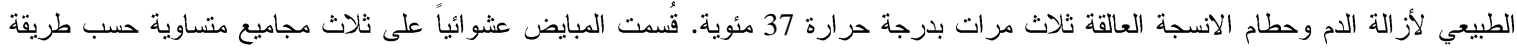

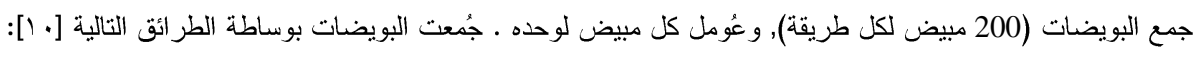
داري طريقة تشريح المبيض (Slicing): وضع المبيض في صحن بتري (Petridish) معقم ذات قطر 90 ملم ويحتوي على 5 مليليتر من وسط محلول دارئ الفوسفات (Phosphate Buffer Sline-England) مع الهيبارين (Heparin-Denmark) وبنسبة 25 وحدة دولية/ مليليتر لهنع تجلط فئل السيائل الجريبي (Follicle Fluid) مُسكت قاعدة المبيض بوساطة الملقط وقطع وشُرح كل سطح المبيض وبعمق 2-3 ملم بإستعمال شفرة جراحية معقمة . (صورة) (Scalpal Juccuya) 


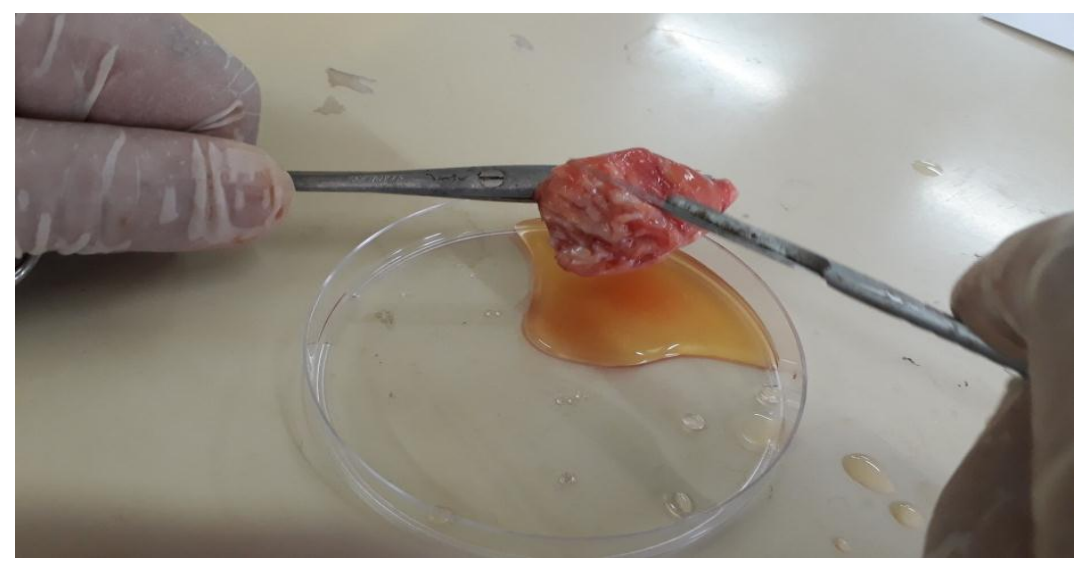

B - Buncture) ( طريقة تقب المبيض وضع المبيض في صحن بتري ذات قطر 90 ملم ويحتوي على محلول دارئ الفوسفات مع الهيبارين, مسكت

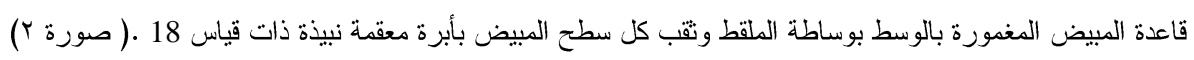

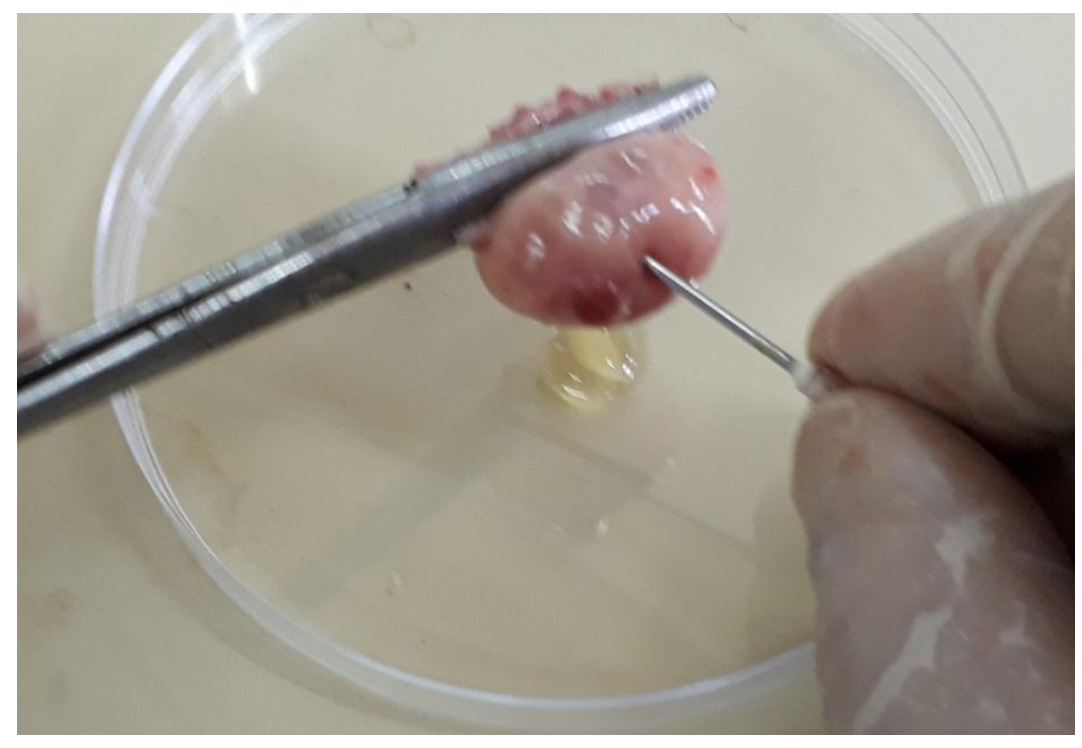

صورة (Y) طريقة ثقب المبيض

- C

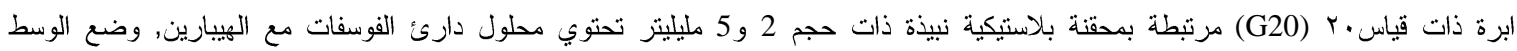

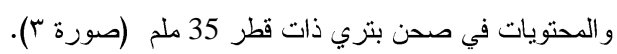




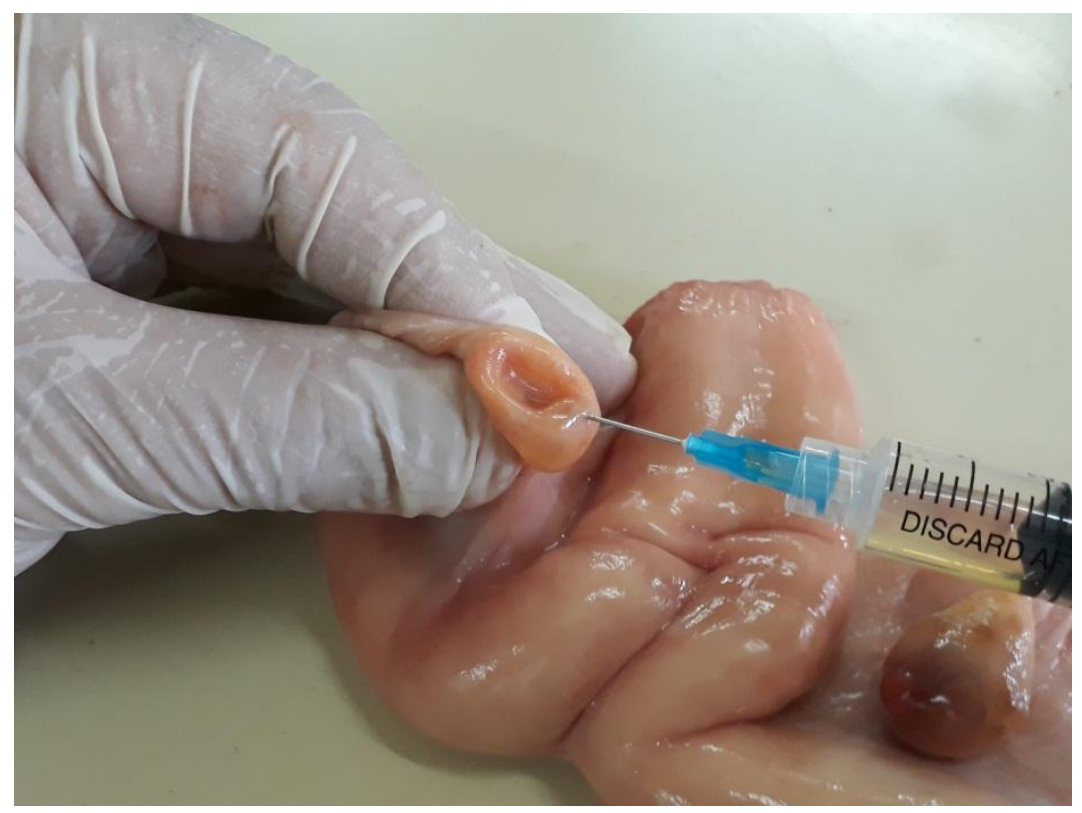

\begin{abstract}
صورة (r) طريقة سحب الجريبة
ترك صحن بتري في جميع العينات لددة 5 دقائق للسماح للبويضات بالترسيب و الأستقر ار في القاع , وفُحصت البويضات تحت المجهر العاكس (Inverted) في القاع وسجل عدد البويضات, ودُرجت (Graded) طبقاً لعدد طبقات الخلايا الركمية مع تجانس الهيولي الى ثلاث مجاميع [4]. 1- بويضات جيدة (Good Oocytes): البويضة محاطة بأكثر من ثلاث طبقات من الخلايا الركمية المبيضية مع تجانس الهيولي. ץ- بويضات متوسطة (Fair Oocytes): البويضة محاطة بأقل من ثلاث طبقات من الخلايا الركمية المبيضية مع تجانس الهيولي. ب- بويضات رديئة (Poor Oocytes): البويضة عارية من الذلايا الركمية المبيضية مع عدم تجانس الهيولي وصورت البويضات مع الركمة المبيضية بوساطة كامرة (Sawyer microscope company) مرتبطة بالحاسوب.
\end{abstract}

استعمل البرنامج الإحصائي SAS (Statistical Analysis System) [11] في تحليل البيانات لدراسة تأثير الطرائق المختلفة (طريقة) في الصفات المدروسة وفق تصميم عشو ائي كامل (CRD)، وقورنت الفروق المعنوية بين المنوسطات باختبار [12 Duncan [12 متعدد الحدود وأستعمل أختبار مربع كاي لمقارنة الفروق المعنوية بين النسب المئوية.

؟ - النتائج و المناقشة

يتبين من نتائج الجدول 1 ارتفاعاً معنوياً (P<0.05) لطريقة تشريح المبيض في عدد البويضات المستحصلة (1639) ومعدل عدد البويضات لكل

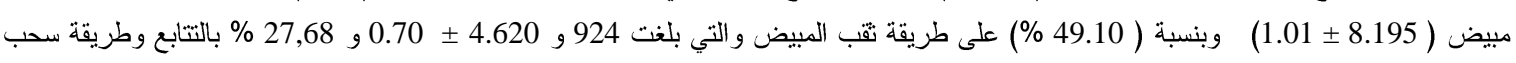
الجريبة وبلغت 775 و 3.875 × 0.24 و 23.21 بالتتابع • ان تفوق طريقة تشريح المبيض في مجموع ومعدل عدد البويضات لكل مبيض ربما بسبب

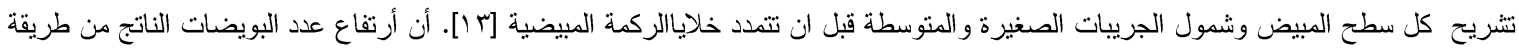

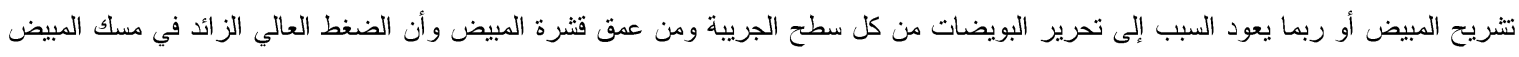

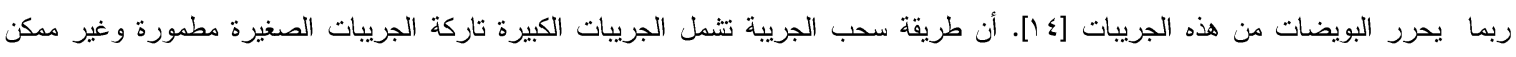

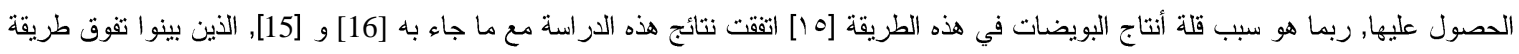

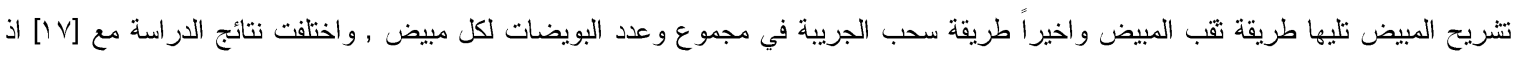

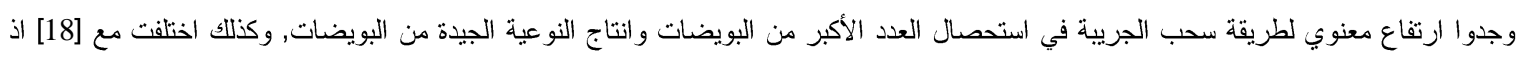


لاحظوا ان البويضات المستحصلة بطريقة سحب الجريبة كانت اكثر من المستحصلة بطريقة تنريح المبيض, ومع [9 19 اذ بينوا ان طريقة سحب

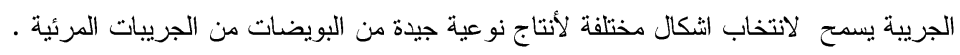

جدول.(1) تأثير ثلاث طر ائث لأستحصال البويضات في عدد البويضات ومعدل أنتاج البويضات لكل مبيض في الأبقار المحلية (المعدل 土 الخطأ (القياسي)

\begin{tabular}{|c|c|c|c|c|c|}
\hline $\begin{array}{c}\text { النسبة المئوية } \\
\text { \% }\end{array}$ & معدل عدد البويضات & عدد البويضات & المبايض & طر ائق الجمع & $ت$ \\
\hline 49.11 & $1.01 \pm 8.195$ & 1639 & 200 & Slicing تشريح المبيض & 1 \\
\hline 27.68 & $0.70 \pm 4.620$ & 924 & 200 & تقب المبيض Puncture & 2 \\
\hline 23.21 & $0.20 \pm 3.875$ & 775 & 200 & سحب الجريبة Aspiration & 3 \\
\hline 100 & $0.01 \pm 5.563$ & 3338 & 600 & المجموع Total & 4 \\
\hline
\end{tabular}

يتوضح من نتائج الجدول 2 ارتفاعاً معنوياً ( P<0.05) لطريقة تشريح المبيض في العدد الكلي للبويضات الجيدة (948 بويضة) (صورة4),

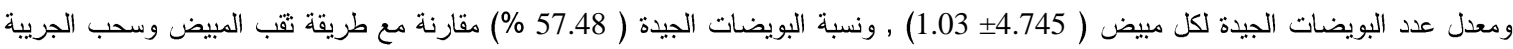
(جدول) , كما أثنارت نتائج الجدول (2) ارتفاعاً معنوياً (P<0.05) لعدد ومعدل عدد البويضات لكل مبيض ونسبة البويضات المتوسطة (صورة 5) المستحصلة بطريقة تشريح المبيض على المستحصلة بطريقة تقب المبيض وطريقة سحب الجزيبة , وبينت النتائج ايضاً تفوقاً معنوياً (2) (P

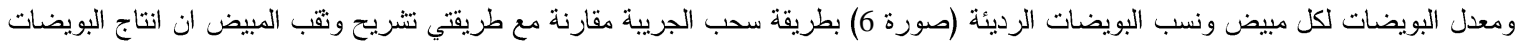
الجيدة والمتوسطة بطريقة تشريح المبيض ربما بسبب تحرير البويضات بأعداد كثيرة من الجريبات السطحية وكذلك الجريبات الموجودة في قنشرة

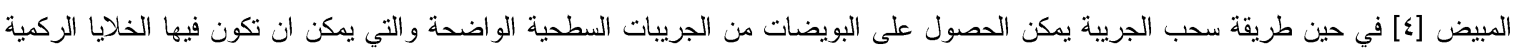

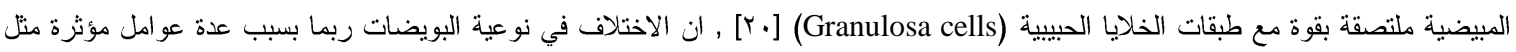

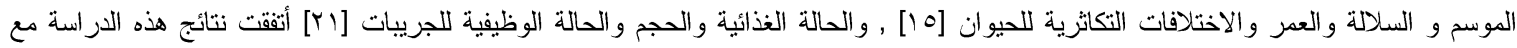

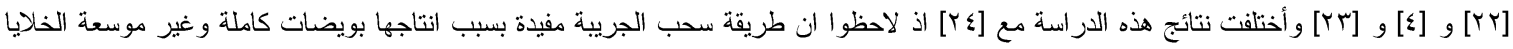
الركمية المبيضية من الجريبات المرئية ذات قطر 2-8 ملم مع نسبة عالية من تدرج البويضات الجيدة ونسبة قليلة من حطام الانسجة وتحتاج لعدد قليل من مرات الغسل .

جدول (r) تأثير طر ائق الجمع في تدرج ونوعية ونسب البويضات (المعدل 土 الخطأ القياسي)

\begin{tabular}{|c|c|c|c|c|c|c|c|}
\hline \multicolumn{6}{|c|}{ تلدرج واعداد ونسب البويضات المستحصلة } & \multirow{2}{*}{ عدد المبايض } & \multirow{2}{*}{ الطرائق } \\
\hline$\%$ & رديئة & $\%$ & متوسطة & 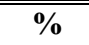 & جيدة & & \\
\hline 17.93 & $\begin{array}{c}0.03 \pm 1.47 \\
\mathrm{~B}(294)\end{array}$ & 24.22 & $\begin{array}{c}0.08 \pm 1.985 \\
\mathrm{~A}(397)\end{array}$ & 57.48 & $\begin{array}{c}1.03 \pm 4.745 \\
\mathrm{~A}(948)\end{array}$ & 200 & المبيض \\
\hline 15.25 & $\begin{array}{c}\text { a } 0.03 \pm 0.705 \\
\mathrm{~B}(141)\end{array}$ & 30.19 & $\begin{array}{c}0.04 \pm 1.395 \\
\mathrm{~B}(279)\end{array}$ & 54.54 & $\begin{array}{c}0.03 \pm 2.52 \\
\mathrm{~B}(504)\end{array}$ & 200 & المبيض \\
\hline 21.03 & $\begin{array}{c}0.01 \pm 0.815 \\
\mathrm{~A}(163)\end{array}$ & 35.11 & $\begin{array}{l}0.02 \pm 1.38 \\
\mathrm{~B}(276)\end{array}$ & 43.35 & $\begin{array}{c}0.01 \pm 1.68 \\
C(336)\end{array}$ & 200 & الجريبة \\
\hline
\end{tabular}

المتوسطات التي تحمل حروف مختلفة تختلف معنوياً (P<0.05) 


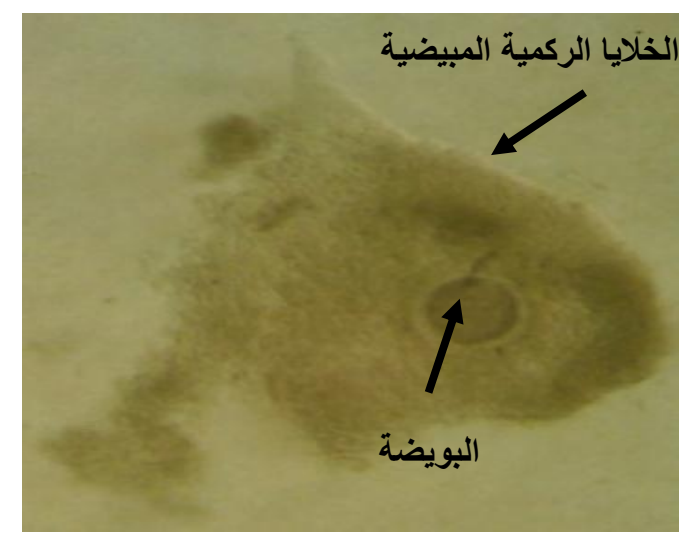

صورة (•) بويضة محاطة بأقل من ثلاث طبقات من الخلايا الركمية المبيضية

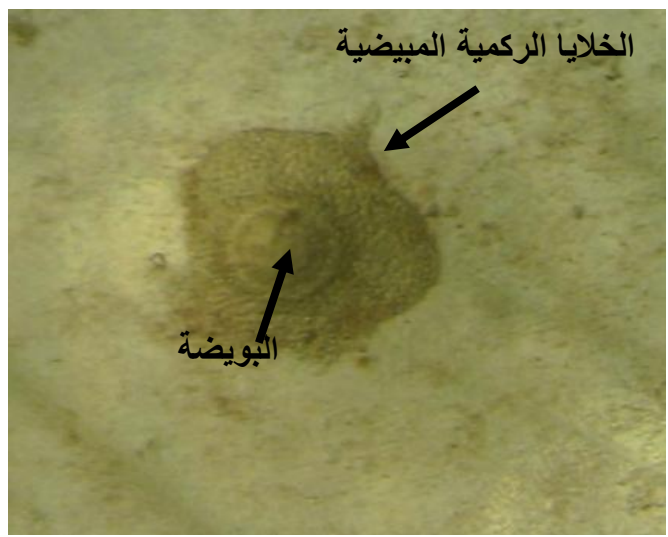

صورة (؛) بويضة محاطة بأكثر من ثلاث طبقات

من الخلايا الركمية المبيضية

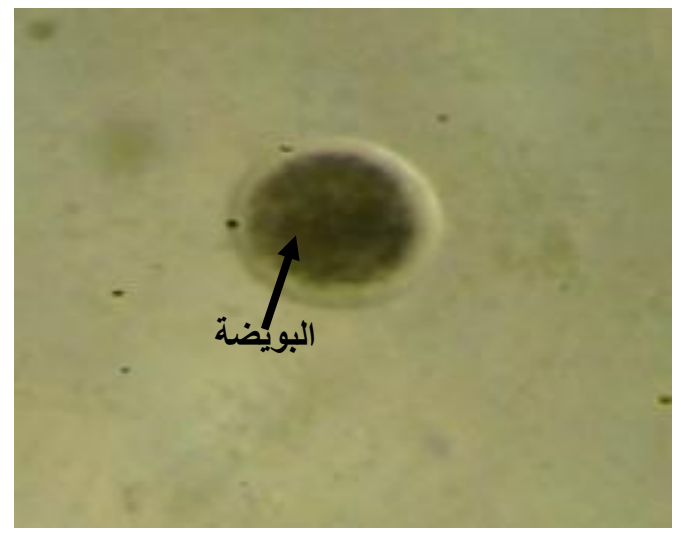

صورة (آ) بويضة خالية من الخلايا الركمية المبيضية

نستتتج من هذه الدراسة ان طريقة تشريح المبيض الطريقة المناسبة للحصول على اعداد كثيرة من البويضات وذات شكل ونو عية جيدة.

\section{CONFLICT OF INTERESTS}

There are no conflicts of interest.

[1] Gardner, D. K.; Michelle, L. and Andrew, J.W. A laboratory Guide to The Mammalian Embryo. New York: Oxford University press. 2004.

[2] Hafez, E.S.E. Hormones, growth factors and reproduction. Reproduction in farm animals., Lea and Febiger, USA, p. 26. 1993.

[3] Sianturi, R. G.; Thein, M.; Wahed, H. and Rosnina, Y. Effect of collection technique on yield of bovine oocytes and the development potential of oocytes from different grades of oocytes. JITV., 7(3):188-193. 2002.

[4] Wang, Z.; Song-dong, Y. u. and Zi-rong, X.. Effects of collection methods on recovery efficiency, maturation rate and subsequent embryonic developmental competence of Oocytes in Holstein cow., Asian Aust J. Anim Sci., 20(4):496-500. 2007

[5] Bohlooli, B. S. and Cedden, F.. Effect of Different Harvesting Techniques on the Recovery and Quality of Bovine Cumulus Oocyte Complexes. Iranian J Applied Anim Sci., 5: 741-74. 2015.

[6] Nowshari, M. A. The effect of harvesting technique on efficiency of oocyte collection and different maturation media on the nuclear maturation of oocytes in camels (Camelus dromedarius). Theriogenol., 63:2471-2481. 2005. 
[7] Tetzner, T. A. D.; Saraiva, N. Z. S.; Perecin, F.; Niciura, S.C.M.; Ferreira, C. R.; Oliveira, C. S. and Garcia, J.M.. The effects of ovalbumin as a protein source during the in vitro pro-duction of bovine embryos. R. Brasilian Zootech.. 40: 2135-2141. 2011.

[8] Gordon, I. Laboratory production of cattle embryos. CAB International, Wallingford, UK. 2003.

[9] Shabankareh, H.K.; Sarsaifi, K. and Mehrannia, T.. In vitro maturation of ovine oocytes using different maturation media: effect of human menopausal serum., J. Assist. Reprod. Genet., 28: 531-537. 2011.

[10] Alves, B. G.; Alves, K. A.; Lucio, A. C.; Martins, M. C. and Silvas,T. H. Ovarian activity and oocyte quality associated with the biochemical profil of serum and follicular fluid from girolando dairy cows postpartum., Anim Reprod Sci., 146: 89-236. 2014.

[11] SAS. Statistical Analysis System, User's Guide. Statistical. Version 9.1 ${ }^{\text {th }}$ ed. SAS. Inst. Inc. Cary. N.C. USA. 2012.

[12] Duncan, D.B. Multiple Rang and Multiple F-test. Biometrics.,11:1-42. 1955.

[13] Das, S. K. and Santra, A. Comparative the efficiency of different oocyte recovery methods from cattle ovaries., Indian J. Anim. Sci., 78: 277-278 . 2008.

[14] Carolan, C. P.; Monaghan, A. Mehmood, P.; Lonergan, M.; Gallagher and Gordon, I. Slicing of bovine ovaries as a means of oocyte recovery., J. Reprod. Fertil., 9(51):51-63. 1992.

[15] Rehman, M. G. M.; Goswarni, P. C.; Yahia, K.; Tareq, M. A. M. and Ali, S. ZCollection of bovine cumulusoocyte-complex (COCs) front slaughterhouse ovaries in Fhattgladesh. Pakistan J. Biology Set., 6(24):2054-2057. . 2003.

[16] Merton, J. S., de Roos,A. P., Mullaart, E., de Ruigh, L., Kaal, L., Vos, P.L. and Dieleman, S.J. Factors affecting oocyte quality and quantity in commercial application of embryo technologies in the cattle breeding industry., Theriogenolog., 59(2):651-67. 2003.

[17] Hamed, K. S.; Mohammad, H. S.; Hadi, H. and Gholamali, M. In vitro developmental competence of bovine oocytes: Effect of corpus luteum and follicle size., Iratt J Reprod Med., 13(10) :615-622. 2015.

[18] Izquierdo, D.; Villamediana, P.; Lopez Bejar, M. and Paramio, M.T. Effect of in vitro and in vivo culture on embryo development from prepubertal goat IVM-IVF oocytes., Theriogenology.,57:1431-1441. 2002.

[19] Kouamo, J.; Nono Fambo, S. M. and Zoli, A. P. Effect of the Stage of Sexual Cycle, Harvesting Technique and Season on Follicular Dynamics and Oocyte Quality of Zebu Cattle under Sudano-Sahelian Climate., Integr J Vet Biosci, 1(1) : 1-7. 2017.

[20] Alm, H.; Torner, H.; Kanitz, W. and Roschlau, K. Influence of oocyte recovery method, in vitro fertilization method and serum source on embryonic development of in vitro matured bovine oocytes. Arch. Tierz., 51: $224-234$. 2008.

[21] Pereira, D.C.; Dode, M.A.N. and Rump, f. R. Evaluation of different culture systems on the in vitro production of bovine embryos., Theriogenology, $63: 1131-1141.2005$.

[22] Takagi, Y.; Mori, K.; Takahashi, T.; Sugawara, S. and Masaki, J. Differences in development of bovine oocytes recovered by aspiration or by mincing., J. Anim. Sci., 70:1923-1927 . 1992.

[23] Carolan, C.; Monaghan, P.;Gallgher, M. and Gordon, I. Effect of recovery method on yield of bovine oocytes per ovary and their Theriogenology., 41: 1061-1068. 1994.

[24] Zarcula, S.M., Cernescu, H., Godja, G. and Igna, V. Effects of recovering bovine oocyte methods on quantity and quality of cumulus-oocyte complexes. Adv. Res. Scientifi c Area-Virtual Conf., 1: 2171-2174. 2012. 